\title{
Compreensão do Desenvolvimento na era do Ultraliberalismo: uma visão conceitual e crítica para realização dos valores Constitucionais
}

\author{
Understanding Development in the era of Ultraliberalism: a \\ conceptual and critical vision to relieve Constitutional Values
}

Jailton Macena de Araújo ${ }^{1}$

Rafael Câmara Norat ${ }^{2}$

\begin{abstract}
RESUMO
O presente artigo tem como objetivo analisar o real significado de desenvolvimento dentro de um contexto de avanço mundial do ultraliberalismo e como essa corrente de pensamento influencia toda uma compreensão do que seria desenvolvimento. Parte-se do pressuposto que crescimento econômico não é desenvolvimento, assim pretende-se sob uma perspectiva dialética criticar a noção de desenvolvimento na concepção liberal e assim construir alternativas para um Estado de Bem-Estar social do qual seja possível um desenvolvimento humano, social e ambiental. Ocorre que houve um avanço do neoconservadorismo nos anos 2010 sob a influências do ultraliberalismo na política brasileira, caracterizada pelo conservadorismo moral e pelo viés ultraliberal na economia. Assim, entrou na pauta do atual governo, uma nova gestão pública a qual a ordem seria a desregulamentação e a privatização. A essa situação, questionase: que tipo de desenvolvimento o Brasil deveria adotar? O Estado brasileiro deve se basear em que tipo de racionalidade para executar suas ações? Os resultados demonstram que a visão de desenvolvimento de viés ultraliberal resta prejudicada, pois não consegue resolver problemas estruturais numa sociedade marcada pela extrema desigualdade como o caso brasileiro. Conclui-se que a concepção de desenvolvimento deve ser encarada de maneira bem mais ampla, dentro de um real contexto de Estado de Bem-Estar social fundamentado numa racionalidade solidária e de efetivação dos direitos sociais contidos na Constituição Federal de 1988.
\end{abstract}

\footnotetext{
1 Doutor em Ciências Jurídicas, área de concentração Direitos Humanos e Desenvolvimento, pela Universidade Federal da Paraíba (2016), mestre em Ciências Jurídicas, área de concentração em Direito Econômico, pela Universidade Federal da Paraíba (2011) e graduado em Direito pela Universidade Federal de Campina Grande (2007). Professor Permanente do Programa de Pós-Graduação em Ciências Jurídicas da Universidade Federal da Paraíba. Docente do Curso de Direito, vinculado ao Departamento de Direito Processual e Prática Jurídica (DDPPJ), do Centro de Ciências Jurídicas (CCJ) da UFPB. Atualmente é Editor Gerente da Prim@ Facie (Revista do PPGCJ). Advogado. Associado ao Conselho Nacional de Pesquisa e Pós-Graduação em Direito (CONPEDI). Tem experiência na área de Direito, com ênfase em Direitos Humanos, atuando principalmente nos seguintes temas: direitos sociais, trabalho, políticas públicas, programa bolsa família, dignidade da pessoa humana e desenvolvimento.

2 Graduação em Direito pela Universidade da Paraíba (2008). Mestrado em Serviço social pela Universidade Federal da Paraíba (2016). Doutorando em Direito pela Universidade Federal da Paraíba. Membro do Corpo Editorial da Cognitio Juris e da Revista Prim@Facie. Advogado. Atua principalmente nos seguintes temas: assédio moral no ambiente de trabalho, prevarização do trabalho e questão social.
} 


\title{
PALAVRAS-CHAVE:
}

Desenvolvimento. Globalização. Estado de Bem-Estar social.

\begin{abstract}
This article aims to analyze the real meaning of development within a context of worldwide advancement of ultraliberalism and how this current of thought influences a whole understanding of what development would be. We start from the assumption that economic growth is not development, so it is intended, from a dialectical perspective, to criticize the notion of development in the liberal conception and thus build alternatives for a social welfare state from which human, social and environmental development is possible. It happened that there was an advance of neoconservatism in the years 2010 with influences of ultraliberalism in Brazilian politics, characterized by moral conservatism and by the ultraliberal bias in the economy. The phenomenon of globalization has led to profound transformations in society in recent decades and for some scholars like Zuleta Puceiro, these changes in the dynamics of economic and social relations should be expanded to the State. Thus, Thus, the State would need to be reformed in order to adapt to the dictates of this new global society, in this way it would enter the agendas of the current governments, a new public management whose order would be deregulation and privatization. In this situation, the question is: what kind of development should Brazil adopt? What kind of rationality should the Brazilian State base on executing its actions? However, the results show that this view of developing an ultraliberal bias remains impaired, as it fails to solve structural problems in a society marked by extreme inequality such as the Brazilian case. It is concluded that the conception of development must be seen in a much broader way, within a real context of the Social Welfare State based on a solidary rationality and the realization of social rights contained in the Federal Constitution of 1988.
\end{abstract}

\section{KEYWORDS:}

Development. Globalization Social welfare state.

\section{INTRODUÇÃO}

O entendimento do que é desenvolvimento pode variar bastante a depender da época, da região a ser aplicado ou até mesmo do viés ideológico dominante. Desta forma, é imperioso que o real significado de desenvolvimento dentro de um contexto de avanço mundial do ultraliberalismo, seja objeto de reflexão, especialmente, em situações como o momento atual de transformações profundas na sociedade global.

É importante que se mencione que, apesar do momento de contingenciamento econômico que se vive, ainda é forte a influência exacerbada das políticas conservadoras, 
especialmente reduzindo o impacto da agenda socioeconômica e limitando o alcance das políticas voltadas ao desenvolvimento em sua acepção constitucional.

Verifica-se que houve um avanço do neoconservadorismo nos anos 2010 sob a influência do ultraliberalismo na política brasileira, bem como a ascensão de uma racionalidade ultraliberal-conservadora caracterizada pelo conservadorismo moral e pelo viés ultraliberal na economia. Assim, têm sido cada vez mais relevantes no debate político nacional, um novo modelo de gestão pública no qual a ordem seria a desregulamentação e a privatização. Em face desse contexto, é possível levantar o seguinte questionamento: que tipo de desenvolvimento o Brasil deveria adotar? O Estado brasileiro deve se basear em que tipo de racionalidade para executar suas ações?

Para tornar possível responder essas questões, pretende-se, a partir de uma abordagem metodológica qualitativa, reconhecer que o crescimento econômico não pode ser entendido como desenvolvimento, assim pretende-se sob uma perspectiva dialética criticar a noção de desenvolvimento na concepção liberal e assim construir alternativas para um Estado de BemEstar social do qual seja possível um desenvolvimento humano, social e ambiental.

Pretende-se, para tanto, apontar alternativas para um outro tipo de desenvolvimento que se conecte com uma racionalidade solidária capaz de fomentar uma transformação social que contemple todos os aspectos que consiste em um real desenvolvimento. Desta feita, estruturase o presente trabalho da seguinte maneira: na primeira seção, imediatamente após esta introdução, será abordado o processo histórico republicano brasileiro e como as políticas públicas encararam a noção de desenvolvimento ao longo do tempo.

$\mathrm{Na}$ seção seguinte será realizada uma análise do texto constitucional vigente, considerando-se que, promulgada logo que retomada a democracia no Brasil, a Constituição Federal de 1988 tenta expressar os anseios de uma sociedade plural que ainda tem graves problemas de desigualdade social. Na última seção, é feito um apanhado das diversas teorias e compreensões sobre o desenvolvimento e como estes devem ser aplicadas, abordando-se os efeitos do neoliberalismo e da globalização, tendo como contraponto o ambíguo desenvolvimentismo aplicado no Brasil no início dos anos 2000. 
De antemão, é possível adiantar que a visão de desenvolvimento de viés ultraliberal resta prejudicada, pois não consegue resolver problemas estruturais numa sociedade marcada pela extrema desigualdade como o caso brasileiro, levando-se a concluir que a concepção de desenvolvimento deve ser encarada de maneira bem mais ampla, dentro de um real contexto de Estado de Bem-Estar social fundamentado numa racionalidade solidária e de efetivação dos direitos sociais contidos na Constituição Federal de 1988.

\section{ASPECTOS HISTÓRICOS SOBRE O DESENVOLVIMENTO NO BRASIL}

Para compreender como a visão sobre o que seria desenvolvimento foi construída no Brasil, precisamos fazer um recorte histórico, a partir do início do período republicano e destacar as disputas de poder que perfizeram ao longo da história e como as doutrinas políticas dominantes de cada período atuaram na concretude de seus ideais.

A corrente política do liberalismo influenciou o pensamento sobre o que seria desenvolvimento, desde os primórdios da república brasileira. A classe dominante da República Velha ${ }^{3}$ construiu uma narrativa em que só através do liberalismo econômico se alcançaria o desenvolvimento, acreditava-se que o desenvolvimento social viria a reboque juntamente com o tão esperado crescimento econômico.

Esse pensamento era bastante conveniente para elite cafeeira que pretendia expandir os seus negócios. Nesse período os dois estados brasileiros que detinham o maior poderio econômico se alternaram no poder para que desta maneira os seus interesses não fossem ameaçados. Entretanto, essa elite cafeeira foi bastante prejudicada com a crise econômica de 1929 e alguns estados descontentes por não participarem do jogo político do país iniciaram uma revolução em 1930 liderada por Getúlio Vargas, o que acarretou com o fim da política do cafécom-leite.

\footnotetext{
${ }^{3}$ República Velha é a denominação dada à primeira fase da República brasileira, que se estendeu da Proclamação da República em 15 de novembro de 1889 até a Revolução de 1930, liderada por Getúlio Vargas.
} 
A era $\operatorname{Vargas}^{4}$ trouxe consigo um novo elemento para o que se esperava do desenvolvimento, o desenvolvimentismo. O governo de Vargas foi marcado por ambiguidades no seu aspecto político, pois Getúlio Vargas tentava conciliar políticas públicas que agradasse tanto a elite empresária quanto a classe operária. Nesse período formulou-se uma reestruturação do Estado (ativo), com a criação de novas agências voltadas para a formulação de políticas econômicas, das quais se destacaram a instituição da Petrobras e do Banco Nacional de Desenvolvimento Econômico (BNDE).

No aspecto do desenvolvimento social, os trabalhadores obtiveram algumas conquistas, houve a criação do ministério do trabalho, a regulamentação da justiça do trabalho e a Consolidação das Leis Trabalhistas (CLT). Vários direitos trabalhistas foram regulamentados como o salário mínimo. A Constituição de 1937 fixou as diretrizes da política social e trabalhista que seria implementada no Estado Novo. Foram confirmados direitos trabalhistas já fixados na Constituição de 1934, como salário mínimo, férias anuais e descanso semanal, e foi também mantida a Justiça do Trabalho, encarregada de dirimir conflitos entre empregados e empregadores. Mas houve uma alteração importante: o princípio da unidade sindical foi restabelecido, e apenas os sindicados legalizados poderiam defender os direitos da categoria que representavam perante o Estado.

No governo de Juscelino Kubitschek, o termo desenvolvimento foi novamente aplicado e sua administração foi marcada por amplos investimentos em transporte, produção de energia e indústrias de base, com a finalidade de proporcionar o crescimento econômico capitalista ao Brasil. Percebe-se que novamente a noção de desenvolvimento aqui erigida estava intrinsicamente ligada ao crescimento econômico.

De fato, JK tinha a ambição de criar um ciclo de desenvolvimento econômico audacioso para sua época, imortalizado pelo lema "50 anos em 5", tendo como base dessa proposta o plano de metas, assentado no desenvolvimento de cinco setores: energia, transporte, indústria, educação e alimentação. Como dito anteriormente, o desenvolvimentismo aplicado por JK era de crescimento econômico, então não é surpreendente que as metas da educação e alimentação

\footnotetext{
${ }^{4}$ Era Vargas é o nome que se dá ao período em que Getúlio Vargas governou o Brasil por 15 anos, de forma contínua (de 1930 a 1945). Esse período foi um marco na história brasileira, em razão das inúmeras alterações que Getúlio Vargas fez no país, tanto sociais quanto econômicas.

${ }^{5} \mathrm{JK}$ fez uma promessa em que ao assumir o governo iria modernizar o Brasil, de tal forma que faria em 5 anos, obras que outro governo levaria até 50 anos para fazer o mesmo.
} 
foram as únicas não alcançadas. Já as demais conseguiram ser cumpridas, devido ao grande investimento estatal e do capital estrangeiro. Entretanto, esses investimentos geraram uma grande dívida externa nacional, outro aspecto negativo foi a crescente inflação no governo JK (CARVALHO, 2002. p. 132).

É importante frisar que a fundamentação ideológica do nacionalismo desenvolvimentista derivava do pensamento da Comissão Econômica para a América Latina (CEPAL), no Brasil houve a criação, em 1955, do Instituto Superior de Estudos Brasileiros (ISEB), órgão vinculado ao Ministério da Educação e Cultura, tinha como objetivo principal a discussão em torno do desenvolvimentismo. O ISEB concebeu uma ideologia nacionaldesenvolvimentista, tendo como tese central a de que a promoção do desenvolvimento econômico e a materialização da nacionalidade compõem duas feições do mesmo processo emancipatório. O desenvolvimento necessitaria, portanto, de uma consciência nacional impulsionada em torno de uma vontade - plano global - de desenvolvimento (CARVALHO, 2002. p. 133).

O governo de João Goulart foi marcado pelo plano trienal de desenvolvimento econômico e social e pela tentativa de implementação das reformas de base. Estas consistiam em medidas para atenuar as desigualdades sociais no Brasil. Dentre as propostas das reformas de base estavam: a agrária, a bancária, a fiscal, a universitária, a urbana e a administrativa. Entretanto a mais polêmica e que ganhou mais destaque foi a de reforma agrária. Esta tinha como meta distribuir de maneira mais equitativa a terra entre os trabalhadores rurais e tinha como pressuposto a necessidade de alterar a exigência prevista na Constituição Federal vigente de que a desapropriação de terras deveria sofrer indenização prévia em dinheiro.

O plano trienal foi idealizado pelo ministro do planejamento, Celso Furtado, que teve o intuito de estabelecer regras e instrumentos rígidos para o controle do déficit público e refreamento do crescimento inflacionário. Celso Furtado foi um economista e intelectual que teve grande influência no governo deste período. Ele elabora uma nova concepção sobre o que seria desenvolvimento levando em consideração a realidade periférica em que o Brasil se encontrava no contexto mundial.

Para Celso Furtado, o subdesenvolvimento é uma forma de organização social dentro do sistema capitalista, sendo um processo estrutural específico e não uma etapa a qual os 
Estados atualmente considerados desenvolvidos tenham passado por ela. Assim, ele nega a ideia de que o subdesenvolvimento seja uma fase para o desenvolvimento econômico, como sugerem as expressões de países "emergentes" e "em desenvolvimento".

Dessa forma, consideraremos o subdesenvolvimento como uma criação do desenvolvimento, isto é, como consequência do impacto, em grande número de sociedades, dos processos técnicos e de formas de divisão do trabalho irradiados do pequeno número de sociedades que se haviam inserido na revolução indústria em sua fase inicial, ou seja, até fins do século XIX. (FURTADO, 2011, p. 88).

Nesse sentido, as nações subdesenvolvidas apresentaram, de acordo com Furtado, um desenvolvimento de industrialização indireto, isto é, uma decorrência do desenvolvimento dos países industrializados. Este encadeamento histórico peculiar do Brasil cunhou uma industrialização subordinada aos países já desenvolvidos e, por conseguinte, não seria capaz de modo algum ser superado sem uma intensa intervenção estatal que redirecionasse o excedente, até então aproveitado para o consumo das elites, para o setor produtivo. Atente-se que isto não expressava uma mudança do sistema produtivo por completo, mas um redirecionamento da política econômica e social do país que induzisse em conta o verdadeiro desenvolvimento social. "Em síntese: desenvolvimento e subdesenvolvimento devem ser considerados como dois aspectos de um mesmo processo histórico, ligado à criação e à forma de difusão da tecnologia moderna (FURTADO, 2011, p. 88)".

Entretanto, as políticas do governo Goulart contrariavam os interesses dos grandes proprietários de terra e foram mal recepcionadas por uma parcela significativa das forças armadas. Assim, no dia primeiro de abril de 1964, foi instaurado o golpe que culminou numa ditadura militar que iria durar vinte e um anos. No decorrer do regime militar, sucedeu um fortalecimento do poder central, principalmente do poder Executivo, representando um regime de exceção, no qual o Executivo se arrogou da função de legislar, em detrimento dos outros poderes estabelecidos pela Constituição de 1946.

A década de 1960 principiou também, uma era de amplas alterações na economia do Brasil, de modernização da indústria e dos serviços, de concentração de renda, de abertura ao capital estrangeiro e do endividamento externo. (GIANNASI, 2011, p. 16). Durante os 21 anos em que os militares estiveram no poder, a economia brasileira expandiu num ritmo quase três vezes maior do que o obtido nos primeiros 21 anos após a volta da democracia. No período em que esse crescimento foi mais acelerado, entre 1967 e 1973, o Produto Interno Bruto (PIB) 
aumentou 10,2\% ao ano, em média, dobrando de tamanho em apenas sete anos. O resultado destoava tanto dos padrões da época que os analistas passaram a chamá-lo de "milagre brasileiro $^{6}$ (FOLHA DE SÃO PAULO, 2014)".

Entretanto, a concentração de renda e a desigualdade foram bastante acentuadas no período da ditadura militar. Os idealizadores do "milagre econômico" acreditavam que era mais importante para o desenvolvimento da nação, o crescimento econômico para depois se pensar na redistribuição de renda. O ministro da fazenda, Delfim Netto, foi o mentor da política econômica brasileira durante os governos militares Costa e Silva, Médici e Figueiredo, ele ficou famoso por comparar o crescimento econômico a um bolo.

Delfim Netto foi duramente criticado pela intensa concentração de renda durante esse período, em resposta, ele afirmou que era necessário aguardar o bolo crescer para, depois, reparti-lo. Contudo o bolo cresceu e jamais foi dividido. A política econômica de Delfim era marcada pelo congelamento dos salários e a elevação das tarifas públicas. Também foi caracterizada por conferir incentivos às exportações e ao investimento estrangeiro no país. (BAGHDASSARIAN, 2019).

O "milagre econômico" perdurou até 1973, após isso houve uma diminuição no crescimento da economia, atrelada ao crash de $1971^{7}$ e também à crise do petróleo. A ditadura militar durou até 1985 e além do autoritarismo e da violação dos direitos humanos, deixou como legado, graves prejuízos econômicos e sérios problemas sociais, dentre elas: dívida externa enorme, ela cresceu mais de 30 vezes: subiu de 3,3 bilhões de dólares, em 1964, para 102 bilhões de dólares $(3.000 \%)$ até 1984 . Isso acarretou em uma crise e baixo crescimento econômico nos anos de 1980 e 1990.

A renda piorou: O poder de compra do salário mínimo caiu a quase a metade, em valores atualizados, o salário mínimo em 1964 era o equivalente a $\mathrm{R} \$ 1.358,24$ e em 1984 era de apenas R\$759,18 (valores corrigidos para 2015 (IGP-DI/FGV). A inflação disparou, a taxa anual subiu de $85 \%$ para $178 \%$. a inflação persistiu alta nos anos seguintes até ser controlada com o Plano

\footnotetext{
${ }^{6}$ Milagre econômico brasileiro é o nome dado à época de crescimento econômico elevado durante a ditadura militar brasileira, entre 1969 e 1973.

7 O crash que se iniciou em junho de 1971, foi o "estouro" da segunda maior bolha especulativa da história brasileira em termos relativos, referente ao número de participantes do processo, em relação à população total, e diversidade de classes sociais, às quais pertenciam.
} 
Real, em 1994. A desigualdade social aumentou: Afora a perda na renda, a economia não conseguiu acompanhar o aumento populacional nas décadas seguintes. $O$ indicador de desigualdade, o índice Gini, só melhorou nos governos civis e apenas nos anos 2000 começou a voltar ao patamar da década de 1960. (SANZ, 2017).

Após a retomada da democracia no Brasil, os governos civis que surgiram após a Ditadura Militar tiveram que lidar com a desigualdade social, o endividamento e a inflação herdados desse período anterior, tendo como destaque a promulgação da Constituição Federal de 1988, cunhada de Constituição Cidadã e será abordada no próximo capítulo. A nova etapa política no país foi caracterizada por inúmeras tentativas de ajustes e pela inserção do país na lógica da globalização e do neoliberalismo e será abordado no último capítulo.

\section{O DESENVOLVIMENTO NA CONSTITUIÇÃO FEDERAL DE 1988}

A Constituição Federal de 1988 marcou um período de retomada da democracia brasileira, após vinte e um anos de ditadura militar, a nova Carta Magna buscava conciliar o anseio dos mais diversos setores da sociedade. A Assembleia Nacional Constituinte de $1987^{8}$ foi prova disso, em meio a políticos, integraram a Constituinte representantes da sociedade civil, com organizações de classe, entidades sociais e religiosas, e lideranças indígenas.

É necessário compreender como o termo desenvolvimento é cunhado na lei fundamental brasileira, como é posto na prática e quais os empecilhos para sua real aplicação. O termo desenvolvimento já aparece no preâmbulo da Constituição Federal de 1988, o desenvolvimento é disposto como um propósito ao qual o Estado Democrático deve se empenhar. No texto constitucional propriamente dito, a primeira menção do termo desenvolvimento é na qualidade de um dos objetivos fundamentais da República Federativa do Brasil, conforme consta do art. $3^{\circ}:$

\footnotetext{
${ }^{8}$ A Assembleia Nacional Constituinte de 1987 é também mencionada como Assembleia Nacional Constituinte de 1988 ou como Assembleia Nacional Constituinte de 1987-1988.
} 
Art. $3^{\circ}$ Constituem objetivos fundamentais da República Federativa do Brasil: I - construir uma sociedade livre, justa e solidária;

II - garantir o desenvolvimento nacional;

III - erradicar a pobreza e a marginalização e reduzir as desigualdades sociais e regionais;

IV - promover o bem de todos, sem preconceitos de origem, raça, sexo, cor, idade e quaisquer outras formas de discriminação. (grifos do autor)

Assim, o desenvolvimento é posto no art. $3^{\circ}$ da CF como algo que a República deve ter como meta fundamental. A primeira conclusão que se pode chegar é de que deve ser um tema constante na agenda governamental, e não uma atenção momentânea ou eleitoreira. Porém que tipo de desenvolvimento nacional a Constituição quer dizer? Seria meramente desenvolvimento econômico ou algo mais? De acordo com André Ramos Tavares, o significado de desenvolvimento inserido no texto constitucional deve ser bem mais amplo, incluindo à melhoria das condições humanas, nas palavras dele:

\begin{abstract}
É preciso, contudo, compreender bem o comando constitucional. Não há palavras inúteis na Constituição, o que significa que não se admite uma hermenêutica voltada a nulificar termos ou trechos constitucionais, assim como não se admite uma postura reducionista de uma eficácia normativa mínima. Também há de se considerar diversas outras proposições constitucionais para construir um significado inicial consistente acerca do comando em apreço. Nesses termos, pode-se concluir, igualmente, que o desenvolvimento de que fala a Constituição é um desenvolvimento vocacionado à melhoria das condições humanas, incluídas aí a dignidade e a liberdade, e não apenas o crescimento econômico. (TAVARES, 2006, p. 133).
\end{abstract}

Em seguida, no inciso IX do art. 21 da Constituição Federal, é mencionado como competência da União "elaborar e executar planos nacionais e regionais de ordenação do território e de desenvolvimento econômico e social". Ou seja, há uma preocupação no texto constitucional em que haja tanto um crescimento da economia quanto um progresso humano e das condições sociais.

Há também no texto constitucional uma atenção em relação ao desenvolvimento e a redução das desigualdades regionais. Visto que há uma disparidade econômica-social entre as regiões norte/nordeste e as regiões centro-sul. Nesse sentido, o artigo 43 reza que: "Para efeitos administrativos, a União poderá articular sua ação em um mesmo complexo geoeconômico e social, visando a seu desenvolvimento e à redução das desigualdades regionais.”. 
Até mesmo no título que trata da Ordem Econômica e Financeira, há uma preocupação com o campo social, há uma mescla de interesses, ora para atender a segmentos do empresariado, ora para tratar da questão social brasileira como podemos constatar no art. 170:

Art. 170. A ordem econômica, fundada na valorização do trabalho humano e na livre iniciativa, tem por fim assegurar a todos existência digna, conforme os ditames da justiça social, observados os seguintes princípios: [...] II - propriedade privada; III função social da propriedade; IV - livre concorrência; [...] VII - redução das desigualdades regionais e sociais;

Há também outra referência que é importante mencionar: o $\S 1^{\circ}$ do art. 174. O caput do art. 174 dispõe sobre a competência normativa e reguladora do Estado sobre a atividade econômica, especificando as funções de fiscalização, incentivo e planejamento. Por sua vez, o $\S 1^{\circ}$ prevê a necessidade de uma lei que harmonize os planejamentos nacionais e regionais de desenvolvimento. Em relação a expressão "atividade econômica", esta deve ser compreendida em sentido amplo e não apenas a atividade econômica em sentido estrito, conforme afirma Eros Grau:

No que tange ao art. 174, no entanto, a expressão atividade econômica é utilizada
noutro sentido. Alude, o preceito, a atividade econômica em sentido amplo. Respeita
à globalidade da atuação estatal como agente normativo e regulador. A atuação
normativa reclama fiscalização que assegure a efetividade e eficácia do quan-to
normativamente definido - daí porque, em rigor, nem seria necessária a ênfase que
o preceito adota ao expressamente referir a função de fiscalização. A atuação
reguladora há de, impõe a Constituição, compreender o exercício das funções de
incentivo e planejamento. Mas não apenas isso: atuação reguladora reclama também
fiscalização e, no desempenho de sua ação normativa, cumpre também ao Estado
considerar que o texto constitucional assinala, como funções que lhe atribui, as de
incentivo e planejamento. Este, por outro lado, não abrange apenas a atividade
econômica em sentido estrito, porém toda a atividade econômica em sentido amplo.
(GRAU, 2005, p. 107).

Assim, em termos gerais, entende-se que a Constituição brasileira, ao tratar acerca da ordem econômica, permite que o Estado atue de forma direta na economia, nos casos em que é indispensável salvaguardar a segurança nacional ou há relevante interesse coletivo. Por conseguinte, verifica-se que as relações entre desenvolvimento e a constituição não devem ser refutadas, sob pena de se desconsiderar a vigência de dispositivos contidos na própria constituição contemporânea. 


\section{DESENVOLVIMENTO NA ERA ULTRALIBERAL}

É necessário apresentar algumas concepções sobre desenvolvimento para que se possa chegar na compreensão atual do desenvolvimento na era ultraliberal e as disputas para outra possibilidade de desenvolvimento.

Primeiramente será abordada a noção clássica, àquela que apresentamos como teoria adotada por diversos governos brasileiros, principalmente na República Velha, desenvolvimento como crescimento econômico. Essa teoria sustenta que o fundamental para o desenvolvimento de uma nação é a acumulação de capital por meio da poupança interna e externa. Dessa forma, observa-se que esse conceito é extremamente universal e restritivo, como se a situação socioeconômica dos estados desenvolvidos fosse capaz de ser estendida a todos os demais países do globo, sendo suficiente que os países subdesenvolvidos superassem as etapas necessárias de acumulação de capital. (OLIVEIRA, p. 41, 2006). Nesse aspecto, as críticas sobre o subdesenvolvimento dos países periféricos apresentadas por Celso Furtado para explicar a realidade brasileira são muito oportunas.

Outra teoria econômica sobre desenvolvimento é a ideia trazida por Joseph Schumpeter, o poder econômico da mudança. Para esse pensador, a permanente inovação tecnológica, seria o motivo capacitado para possibilitar à sociedade o potencial de crescimento, ou no vocabulário de Schumpeter o poder econômico da mudança. (LUCHT, 2004).

\footnotetext{
O desenvolvimento econômico se confunde aqui também com o crescimento, mas os pressupostos que Schumpeter adota para seu modelo nos dizem um pouco sobre as condições que esse acha essencial para que ocorra um crescimento. A propriedade privada, a divisão do trabalho e a livre competição. (LUCHT, 2004, p. 23).
}

Há também duas correntes que derivaram da tradição cepalina ${ }^{9}$, a primeira é a teoria estruturalista, a qual sustenta, em resumo, que as estruturas atualmente existentes atuam sobre o processo de desenvolvimento e que não só o crescimento econômico é importante para o desenvolvimento, mas igualmente a distribuição de renda. Essa abordagem tem como grandes defensores o já citado, Celso Furtado e o ex-diretor da CEPAL, Raúl Prebisch. Este sustentava a ideia de que a desigualdade econômica e o desenvolvimento distorcido eram uma

\footnotetext{
${ }^{9}$ Cepalina aqui se refere à Comissão Econômica para a América Latina - CEPAL.
} 
característica estrutural inerente à troca global do sistema. Os arquétipos estruturalistas destacavam os desequilíbrios internos e externos derivados da estrutura produtiva e suas interações com a relação de dependência que os países em desenvolvimento tinham com o mundo desenvolvido. (FURTADO, 2011).

A outra teoria provinda da tradição cepalina é a teoria da dependência. Esta foi defendida pelo sociólogo e ex-presidente do Brasil, Fernando Henrique Cardoso. Essa doutrina apregoa que temas políticos também são possíveis de instaurar o desenvolvimento de certos estados, produzindo os países de centro, ao lado dos países de periferia. Para essa corrente, não existe uma "simples diferença de etapa ou estágio de sistema produtivo, mas também de função ou posição dentro de uma mesma estrutura econômica internacional de produção e distribuição." (CARDOSO; FALETTO, 2000, p. 26).

Entretanto, a Teoria da Dependência no transcorrer da década de 1970 adentrou em colapso, a produção autoral vinculada a ela enfraqueceu, sobretudo a começar do final dessa década. Suportou um revés inicial com o golpe do Chile (1973). Essa teoria foi altamente criticada, pois teria influenciado o governo chileno de Salvador Allende. Seus críticos afirmam que assim como a experiência fracassou, a teoria da dependência teria tido o mesmo destino (BAPTISTA, 2009).

No final da década de 1970 e início da década de 1980 surge uma nova teoria atuando no campo político, a neoliberal. As mudanças que ocorreram na década de 1980, a partir da crise do capital e a ascensão de governos como o do presidente dos Estados Unidos Ronald Reagan (1980-1988), Margaret Thatcher no Reino Unido e a emergência da implementação para os países em desenvolvimento das medidas econômicas elaboradas pelo consenso de Washington ${ }^{10}$ reverteu na consolidação do neoliberalismo na América Latina, e nos anos 1990 na globalização.

De acordo com o receituário neoliberal para o desenvolvimento econômico, dez medidas são indispensáveis, como sintetiza Pfeiffer:

(1) disciplina fiscal (com o argumento de que atos e contínuos déficits fiscais contribuem para a inflação e fugas de capital); (2) redução dos gastos públicos; (3) reforma tributária; (4) taxas de juros de mercado (ou seja, ela não deve ser

\footnotetext{
${ }^{10} \mathrm{O}$ Consenso de Washington é uma conjugação de grandes medidas que se compõe de dez regras básicas para promover o "ajustamento macroeconômico" dos países em desenvolvimento que passavam por dificuldades.
} 


\begin{abstract}
determinada pelo Estado, mas pelo mercado); (5) taxa de câmbio competitiva (ou seja, que favoreça exportações, tornando-as mais baratas para o comércio exterior); (6) abertura comercial (eliminação de barreiras para o comércio exterior); (7) investimento direto estrangeiro, com redução (ou até mesmo eliminação) de restrições; (8) privatização das empresas estatais; (9) desregulamentação; e (10) proteção dos direitos de propriedade. (PFEIFFER, 2011, p. 17-29).
\end{abstract}

Assim, alguns pensadores, como o cientista político Zuleta Puceiro (2010), acreditam que a adoção de políticas neoliberais seja realmente necessária para o continente latinoamericano e sustentam que o fenômeno da globalização é uma tendência natural, pois estaríamos numa transição de uma sociedade industrial para uma sociedade baseada na primazia da informação e do conhecimento.

Nesse sentido, desenvolvimento estaria atrelado a uma economia global no qual ocorre um fluxo internacional de bens e serviços, caracterizado por um deslocamento de unidades produtivas. Para isso, seria necessária a derrubada de fronteiras geográficas, econômicas, políticas e culturais. Para Puceiro (2010), justifica-se a implementação do modelo neoliberal e a adoção da globalização porque houve uma grave acumulação em décadas anteriores da dívida externa nos países da américa latina, por isso seria necessário o controle de gastos públicos e uma disciplina fiscal rígida para controlar a inflação. Outro aspecto apontado por esse autor estaria na tendência mundial dos programas de privatização, justificado pelo problema da corrupção e ineficiência nas estatais.

Esse tipo de pensamento foi dominante na América Latina durante as décadas de 1980 e 1990, entretanto no início dos anos 2000, houve uma guinada no modelo de governança com a ascensão de líderes políticos de esquerda como o ex-presidente Luiz Inácio Lula da Silva.

Os anos 2000 no Brasil foram marcados por um grande crescimento econômico no governo Lula (2003-201) que oscilava entre políticas econômicas tidas como neoliberais como a alta taxa de juros para conter a inflação, bem como as políticas sociais de redistribuição de renda como o bolsa família. Houve um aumento nos níveis de escolarização, e nessa época, houve uma diminuição da extrema pobreza no Brasil e uma ascensão de uma parcela da classe pobre para a classe média. Esse fenômeno foi avaliando como inclusão social; uma vez que na perspectiva neoliberal o aumento de renda está atrelado à inclusão social, mesmo que essa parcela da população não tenha acesso a serviços de qualidade em setores básicos como educação e saúde. (RODRIGUES, 2016). 
Porém no ano 2008, houve uma nova crise econômica global. Esse colapso financeiro iniciado no mercado imobiliário dos Estados Unidos reverberou nos demais países, inclusive no Brasil. Uma onda neoconservadora conduzida por lideres cristãos, principalmente de vertente pentecostais dos Estados Unidos e a bancada $\mathrm{BBB}^{11}$ no Brasil conseguiram eleger líderes da ultradireita. Segundo, Marina Lacerda, autora do livro "O novo conservadorismo brasileiro", o neoconservadorismo é:

É fundado na tríade militarismo, absolutismo do livre mercado e família tradicional. Esta ideologia embasou a eleição de Reagan o golpe chileno e o sistema econômico criado pro Pinochet, entre outros. Ele coloca em cheque as balizas do sistema internacional de direitos humanos e da própria democracia como repertório institucional das disputas por direitos e por garantias para indivíduos e minorias sociais e políticas. (LACERDA, 2019).

Assim foi possível a eleição de políticos como Donald Trump nos Estados Unidos e Jair Bolsonaro no Brasil. No caso brasileiro, o grande expoente da política ultraliberal é o atual ministro da economia, Paulo Guedes. Entre as principais políticas econômicas orquestradas por Guedes estão a reforma da previdência, já aprovada em 2019; as privatizações das estatais que devem iniciar no ano de 2020. Ele também propõe a abertura total do nosso mercado de câmbio e fazer a economia brasileira refém do financismo global.

Assim, para a "racionalidade ultraliberal-conservadora" que exsurge, a noção de desenvolvimento expressada na Constituição Federal de 1988 se torna um empecilho para a aplicação de suas políticas ultraliberais. De tal forma que simplesmente algumas são ignoradas (nos casos de dignidade da pessoa humana LGBT), outras têm os recursos contingenciados (nos casos das universidades públicas) e outros casos buscam uma alternativa mais radical como é a situação do Sistema Único de Saúde (SUS), bem como denuncia o ex-ministro da saúde, Arthur Chioro:

\footnotetext{
O atual governo ameaça o princípio de universalidade do SUS. O projeto é reduzir ao máximo a atenção básica em saúde, dirigida exclusivamente para aqueles que não podem pagar, para que todos os demais sejam induzidos a buscar atendimento no mercado. A situação crônica de subfinanciamento do sistema, agravada desde a aprovação da Emenda Constitucional 95 - que congelou por 20 anos os investimentos sociais - evolui agora para um quadro de "desfinancimento". (CHIORO, 2019).
}

\footnotetext{
${ }^{11}$ A Bancada BBB é um termo usado para referir-se conjuntamente à bancada armamentista, bancada ruralista e à bancada evangélica no Congresso Nacional do Brasil. As agendas das bancadas estão alinhadas à direita política e ao conservadorismo brasileiros.
} 
Diante dessa racionalidade ultraliberal de desenvolvimento, da qual Dupas (2007) acusa como "o mito do progresso" se faz necessário pensar em uma alternativa para um outro tipo de desenvolvimento.

\begin{abstract}
No alvorecer do século XXI, o paradoxo está em toda parte. A capacidade de produzir mais e melhor não cessa de crescer e é assumida pelo discurso hegemônico como sinônimo do progresso trazido pela globalização. Mas esse progresso, discurso dominante das elites globais, traz também consigo exclusão, concentração de renda, subdesenvolvimento e graves danos ambientais, agredindo e restringindo direitos humanos essenciais. (DUPAS, 2007, p.73).
\end{abstract}

Há alternativa, outra perspectiva sobre desenvolvimento deixou-se para abordar agora para ser apresentado como mais uma opção: a teoria do desenvolvimento como liberdade de Amartya Sen (2005). Para essa concepção, o fundamental elemento e a principal finalidade do desenvolvimento de uma sociedade é a liberdade humana, seu alargamento e sua expansão, a fim de que as pessoas possam escolher levar a vida que consideram dignas viver. A liberdade, assim, possui duas dimensões distintas: uma instrumental e outra constitutiva do desenvolvimento humano, e o desenvolvimento deve se dar tanto pela remoção de obstáculo quanto pela propiciação de oportunidades para os indivíduos exercerem e usufruírem de suas liberdades pessoais. (SEN, 2005).

Nas palavras de Sem (2005, p. 25), “as liberdades não são apenas os fins primordiais do desenvolvimento, mas também os meios principais"e, além disso, conforme essa compreensão, o rol das liberdades instrumentais é o seguinte: (1) liberdade políticas, (2) facilidades econômicas, (3) oportunidades sociais, (4) garantias de transparência e (5) segurança protetora.

Em termos práticos uma alternativa viável ao desenvolvimento da era ultraliberal é a retomada/adoção ${ }^{12}$ do Estado de Bem-Estar Social, pois como afirma Delgado (2007), o EBES teria sido uma das mais complexas, abrangentes e bem-sucedidas construções da civilização ocidental:

O EBES sintetiza, em sua variada fórmula de gestão pública e social, a afirmação de valores, princípios e práticas hoje consideradas fundamentais: democracia, liberdade, igualdade, valorização do trabalho e do emprego, justiça social e bem-estar. (DELGADO; PORTO, 2007, p. 24).

\footnotetext{
${ }^{12}$ Retomada para os países líderes do capitalismo na Europa e Estados Unidos. Adoção para os países latinoamericanos que sequer conseguiram construir efetivos Estados de Bem-Estar Social.
} 
Bem como a superação da racionalidade ultraliberal-conservadora para a aceitação de uma racionalidade pautada na solidariedade, consoante defende Araújo (2016):

\begin{abstract}
A racionalidade solidária estabelece a necessidade de releitura da ordem social, que acaba por plasmar a revitalização de valores esquecidos no contexto econômico, como justiça social, dignidade, bem-estar, desenvolvimento humano, participação, promoção social, inserção, inclusão, distribuição de renda e, em especial, o trabalho. Esse cartel de valores implica a adoção de uma teoria que supera a mera acomodação formal. Sob a ótica solidária, esses valores devem ser postos em prática e ampliados na maior medida possível. (ARAÚJO, 2016, p. 255).
\end{abstract}

Dessa forma, o desenvolvimento torna-se legítimo condutor de mudanças nas políticas públicas para ser concretizado nas ações estatais. Ou seja, o Estado deve ser orientado por uma racionalidade que atenda as premissas normativas contidas na Carta de 1988.

Assim, o caráter intervencionista do Estado de Bem-Estar Social torna possível políticas públicas indispensáveis ao desenvolvimento, seja no aspecto econômico com a gestão racional do câmbio, gestão racional do crédito e seus juros, dar prioridade a eixos econômicos estratégicos (energia, saneamento básico e transporte), seja no aspecto social com os investimentos na saúde, educação emprego e moradia.

\title{
5 CONCLUSÃO
}

A compreensão acerca do que seja desenvolvimento, como foi visto neste artigo, esteve sempre atrelada ao pensamento do grupo dominante de cada época. O processo histórico brasileiro nos mostra que nem sempre houve consenso sobre o tipo de desenvolvimento deveria ser adotado no Brasil. Haja vista, as inúmeras conspirações, golpes e tomadas de poder, o Brasil oscilava entre liberalismo econômico e desenvolvimentismo estatizante.

Embora todos esses traumas históricos tenham por vezes trazido crescimento econômico, vide a época da ditadura militar instaurada no ano de 1964, esses não foram capazes de atenuar os problemas estruturais da sociedade brasileira. Assim, resta claro que apenas crescimento econômico não é desenvolvimento. 
Diante dessa afirmação, a concepção de desenvolvimento deve ser ampliada para abarcar também o desenvolvimento humano, social e ecologicamente sustentável. Assim, a interpretação do termo desenvolvimento que aparece na Constituição Federal não pode ser restritivo. Embora atualmente estejamos vivenciando uma guinada histórica neoconservadora e ultraliberal, a defesa intransigente da lei fundamental brasileira deve ser mantida em foco para que outros ataques a direitos fundamentais não sejam concretizados.

O Capital experimenta um processo de crise continuada que vem desde antes da última crise (2008) e, as crises econômicas do capitalismo irrompem em tempo cada vez mais breve, não é tão difícil prever, que a próxima crise de superprodução que está por vir terá efeitos assoladores. Diante dessas crises, os direitos sociais, individuais e trabalhistas conquistados em grandes lutas, inclusive em guerras, no século passado se tornaram um ponto de estagnação para o lucro dos capitalistas.

Acreditar que há alternativas possíveis a era ultraliberal se faz cogente. Apresentamos outras teorias sobre desenvolvimento que são mais inclusivas e socialmente democráticas. Coloca-las em prática será uma tarefa árdua e com um custo político muito elevado, mas só assim, pensando em alternativas é que conseguiremos avançar para uma sociedade mais justa, solidária, democrática e menos desigual.

\section{REFERÊNCIAS BIBLIOGRÁFICAS}

ARAÚJO, Jailton Macena de. Função emancipadora das políticas sociais do Estado brasileiro: conformação das ações assistenciais do Bolsa Família ao valor social do trabalho. 400f. Tese (Doutorado em Ciências Jurídicas), Universidade Federal da Paraíba, Centro de Ciências Jurídicas, João Pessoa, 2016.

BAGHDASSARIAN, William. Fazer o bolo crescer para depois dividi-lo. 2019. Disponível em: <https://www.gazetadopovo.com.br/opiniao/artigos/fazer-o-bolo-crescer-para-depoisdividi-lo/>. Acesso em: 27 jan. 2020.

BAPTISTA FILHO, Almir Cezar de Carvalho. Dinâmica, determinações e sistema mundial no desenvolvimento do capitalismo nos termos de Theotônio dos Santos: da Teoria da 
Dependência à Teoria dos Sistemas-mundo. 2009. 99 f. Dissertação (Mestrado) - Curso de Economia, Ufu, Uberlândia, 2009.

CARDOSO, Fernando Henrique; FALETTO, Enzo. Dependência e desenvolvimento. In: BIELSCHOWSKY, Ricardo (org.). Cinquenta anos de pensamento na Cepal. Rio de Janeiro: Record, 2000

CARVALHO, José Murilo de. Cidadania no Brasil. O longo Caminho. $3^{\text {a }}$ ed. Rio de Janeiro: Civilização Brasileira, 2002.

DELGADO, Mauricio Godinho; PORTO, Lorena Vasconcelos (org.). O Estado de Bem-Estar Social no Sec. XXI. São Paulo: LTr, 2007.

DUPAS, Gilberto. O Mito do Progresso, Novos Estudos, 77, março, 2007.

FOLHA DE SÃO PAULO (São Paulo). Tudo sobre a Ditadura Militar. 2014. Disponível em: $<$ https://arte.folha.uol.com.br/especiais/2014/03/23/o-golpe-e-a-ditadura-militar/aeconomia.html>. Acesso em: 27 jan. 2020.

FURTADO, C. Raízes do Subdesenvolvimento, 2. ed. Rio de Janeiro: Civilização Brasileira, 2011.

GIANNASI, Carlos Alberto. A doutrina de segurança nacional e o "milagre econômico" (1969/1973). 2011. 313f. Tese (Doutorado). Universidade de São Paulo.

GRAU, E. A ordem econômica na constituição de 1988: intepretação e crítica. 9. ed. São Paulo: Malheiros, 2005.

LACERDA, Marina Basso. O novo conservadorismo brasileiro: de Reagan a Bolsonaro. Porto Alegre: Editora Zouk, 2019.

LUCHT FILHO, Horst. Desenvolvimento $\mathrm{x}$ crescimento econômico: uma análise histórica das teorias. 2004. Disponível em: <http://www.peteconomia.ufpr.br/banco_de_arquivos/00020_TRABALHaO.PDF>. Acesso em: 30 jan. 2020.

OLIVEIRA, G. B.; Uma discussão sobre o conceito de desenvolvimento. In: OLIVEIRA, G. B.; SOUZA-LIMA, J. E. (org.) $O$ desenvolvimento sustentável em foco: uma contribuição multidisciplinar. São Paulo: Annablume, 2006.

PFEIFFER, Roberto Augusto Castellanos. Desenvolvimento. In: Fragmentos para um dicionário crítico de direito e desenvolvimento. São Paulo: Ed. Saraiva, 2011.

PUCEIRO, Z. O processo de Globalização e a Reforma de Estado. In: FARIA, J. E. (org.) Direito e globalização: implicações e perspectivas. 2. tiragem. São Paulo: Malheiros, 2010.

SANZ, Beatriz; MENDONÇA, Heloísa. O lado obscuro do 'milagre econômico' da ditadura: 0 boom da desigualdade. 2017. Disponível em: <https://brasil.elpais.com/brasil/2017/09/29/economia/1506721812_344807.html>. Acesso em: 27 jan. 2020. 
SEN, Amartya K. Desenvolvimento como liberdade. Trad. Laura Teixeira Mota. São Paulo: Companhia das Letras, 2005.

TAVARES, André Ramos. Direito Constitucional Econômico, São Paulo: Método, 2006.

Data de Submissão: 18/04/2020

Data de Aceite: 20/05/2020 